\title{
Teaching wireless communications courses: An experiential learning approach
}

\author{
Hugo G. Espinosa ${ }^{1}$, Thomas Fickenscher ${ }^{1,2}$, Nickolas Littman ${ }^{1}$, David V. Thiel ${ }^{1}$ \\ ${ }^{1}$ School of Engineering and Built Environment, Griffith University, Brisbane, Australia, h.espinosa@griffith.edu.au, \\ n.littman@griffith.edu.au, d.thiel@griffith.edu.au \\ ${ }^{2}$ Helmut-Schmidt-University, Hamburg, Germany, thomas.fickenscher@hsu-hh.de
}

\begin{abstract}
Student engagement continues to be a major challenge, particularly in electromagnetics courses. This is independent of whether courses are compulsory or elective. This paper presents an approach to assessing students that provides them with an opportunity for experiential learning, following Kolb's learning cycle. Final year students are required to develop and complete two experimental projects over the 12-week trimester. At the outset of each project, pairs of students choose a three-line project outline; projects are unique to each two-person group with an obscure but practical industrial outcome designed to complement the lecture material. To succeed, students must continue to discuss their project strategies, measurements and final applications with the teaching team throughout the trimester. Students have rated the course experience very highly, and in some cases, their projects have enhanced their post-graduation employment opportunities in the field directly related to one of their projects.
\end{abstract}

Index Terms-experiential learning, electromagnetics, wireless communications, antennas, teaching.

\section{INTRODUCTION}

Electromagnetics provides the basic foundation for systems and components in wireless communication, lightwave technology, radar, antennas, microelectronics and many more. Teaching advanced communications courses is an important part of undergraduate and graduate electrical, electronics and microwave engineering education. Despite its importance, an increasing lack of interest in the field of electromagnetics is observed among students. In order to address this problem, platforms for the dissemination of new and trending strategies in electromagnetic education have been established. These include the IEEE MTT Education Forum [1], the upcoming special issue of the IEEE Antennas and Propagation Magazine: "From Engineering Electromagnetics to Electromagnetics Engineering: Teaching/training next generations", and the convened session Education in Electromagnetics, Antennas, and Microwave from EuCAP 2020.

Furthermore, there is a world-wide awareness of the challenges faced in the methodology and practice of electromagnetics teaching and learning [2, 3]. Several initiatives have been made to move teaching from traditional face-to-face focusing on analytical or semi-analytical approaches towards practice-discovery sessions decoupling to a certain extent the mathematics from the physical understanding, so that the student will be motivated and engaged into electromagnetics before taking the burden of heavily mathematical constructs [4]. Some of these initiatives include project-based learning $[5,6]$, problembased learning [7], flipped classroom [8], experiential learning [9] and other pedagogical approaches [10]. Such strategies intensively engage the student interactively in assigned pre-work based on conceptual questions and realistic examples in order to develop their problem-solving skills.

The different initiatives in electromagnetics education have sparked the development of several Computer-Aided Design (CAD) tools, virtual laboratories, electromagnetic (EM) solvers and Matlab®-based computational tools to support the curriculum. Some examples can be found in [1115], they all, however, share the same objectives: to increase student skills and engagement, enhance student learning outcomes, and improve knowledge retention.

With the increase of engineering practice and internships before graduation, it is important to provide engineering students with sufficient technical abilities and practical skills that are required in industry. Employers often require engineering graduates with not only technical knowledge, but also 'hands-on' abilities. These skills may be developed by designing activities (e.g., assignments) that provide students with self-driven experiential learning opportunities. According to Kolb [16], experiential learning is defined as "the process whereby knowledge is created through the transformation of experience", in other words, it is the process of 'learning by doing', and it addresses the demand for meaningful content experiences [17]. In this paper, an experiential learning approach to an Advanced wireless communications course is presented. The structure of the course along with examples of student work are discussed, and an assessment of the effectiveness of the learning approach is evaluated by means of student feedback.

\section{METHODS}

The undergraduate and post-graduate course 'Advanced Communication Systems' was used in this study. The course is part of the 4-year Bachelor in Electronic Engineering at Griffith University, Nathan Campus, Queensland, Australia. 
The course covers theoretical and practical aspects of microwave and UHF systems and components, and their applications in wireless communications systems. The teaching modules include microwave circuits and measurements, radio navigation, mobile wireless communications systems, radar, and smart antenna systems. Some of the modules are given by guest lecturers with expertise and experience in both academia and industry. The course is designed to acquaint students with leading-edge technologies in the communications field. Students gain experience in the theory and practical implementation of a variety of communications technologies.

The course assumes an understanding of the application of Maxwell's equations to radiating systems. Students work in self-selected pairs to undertake research and development into two discrete and specified tasks. In each case, the outcome is a report on that task, which includes a summary of background knowledge, experimental and theoretical analysis of the task, results and a reflective conclusion. The generic skills include task formulation, critical thinking and analysis, teamwork and report construction. A major part of this course is self-driven experiential learning through independent projects and continuing engagement with the teaching team.

\section{A. Structure of the course}

The course is offered in a 12-week period once a year; it consists of 24 hours of lectures $(1 \times 2$ hrs/week) and 33 hours of laboratories $(1 \times 3 \mathrm{hrs} /$ week $)$. After completing the course, students should be able to:

- Assess reported outcomes using critical thinking and analysis based on engineering principles.

- Create an experimental plan, which includes verification of the experimental outcomes.

The course assessment is as follows: Assignment 1: 20\%, Assignment 2: 20\% and Final examination: 60\%. Significant emphasis is placed on the two assignments, given that a communications engineer requires both a strong theoretical understanding of the material and some practical and numerical modelling experience.

For both Assignments 1 and 2, students have 6 weeks to conceive, design, implement, test, and report the outcomes of the project. Students are asked to provide a brief explanation of the theory, the experimental/numerical results, error calculation and strong verification of the results through a comparison with other data. The assessment is based on the submission of a report with the following sections: Title, Abstract, Theory, Experimental methods, Results, Discussion, Reflection, and Conclusions. While students may work on the project in pairs, individual submissions of the report are required, reflecting the student's individual work.

Assignments are marked out of 20 marks each. The marking scheme is based on the following scale:

- 15-20: excellent review of the problem, clear understanding of the measurements and analysis of results.
- 10-14: some review of the problem, some understanding of the measurements and analysis of results.

- 0-9: inadequate work completed, poor understanding of the problem and the practical techniques, poor analysis of results.

During the laboratory sessions, students have access to specialized equipment such as vector network analyzers, spectrum analyzers, signal generators, log RF detectors, Xband waveguides, Gunn oscillators, frequency counters and antenna test site. Software includes NEC $\AA$, Matlab ${ }^{\circledR}$, Altium ${ }^{\circledR}$, Microwave Office ${ }^{\circledR}$.

\section{B. Assignment topics}

For Assignment 1, students receive a list of topics at the beginning of the course. They select a topic on a 'first in' basis and that topic is no longer available to the rest of students. The list of Assignment 1 topics is carefully designed based on current technology trends and potential applications in industry. Every project is described in no more than three lines. The list provided to students includes around 25 available projects. Some examples include:

1. Scattering of a 3-D printed conductor at X-band.

2. Effects of a C-slot on microstrip patch antenna bandwidth.

3. Buried monopole antenna performance using a finite ground plane at $2.8 \mathrm{GHz}$. The antenna will be buried in dry sand and both the antenna impedance and the radiation pattern will be measured.

4. Location uncertainties of a $500 \mathrm{MHz}$ transmitter using two spaced receivers as a function of time and $x-y$ position.

5. Cityscape scattering at $\mathrm{X}$-band using a simple collinear monopole antenna.

6. The effects of bends on a halfwave dipole antenna on a flexible paper substrate at $1 \mathrm{GHz}$. The antenna will be constructed using adhesive copper foil.

7. Microstrip T-match for a monopole antenna at 800 $\mathrm{MHz}$ on FR4 and plastic using a coplanar ground plane.

8. Underwater patch antenna properties at $2 \mathrm{GHz}$ using a microstrip feed and a quarter wave transformer.

9. X-band properties of concrete.

10. Open stub effective permittivity measurements on skin and the determination of anisotropy.

Once the student submits the first assignment on-line, the list of projects for Assignment 2 is made available through Blackboard. Students have another 6 weeks for the submission of the second report.

\section{Experiential learning cycle}

The assessment incorporated in this course is intended to provide students with opportunities for experiential learning. Kolb's experiential learning model [16, 18] outlines four stages of experiential learning: concrete experience, reflective observation, abstract conceptualization, and active experimentation (Fig. 1). Each of the four stages is 
considered to be integral to experiential learning. The learner can enter the cycle at any stage by keeping the logical sequence. The vertical axis in Figure 1 represents the knowledge grasping dimension (perception), while the horizontal axis represents knowledge transformation (process) [19].

Students are given a three-line description of the project. From this, they design the project protocol, based on fundamental theory provided during lecture time, enabling them to gain concrete, hands-on experience. In the second stage, students assess/reflect the initial outcomes of the experience. Project management, group work and studentto-student interaction are important for a meaningful reflection; the questions 'what worked?' and 'what didn't work?' arise. In the third stage, students draw conclusions from the experience, with support from teaching staff. In the fourth stage students test the experience and create a strategic plan for the design and development of the second assignment.

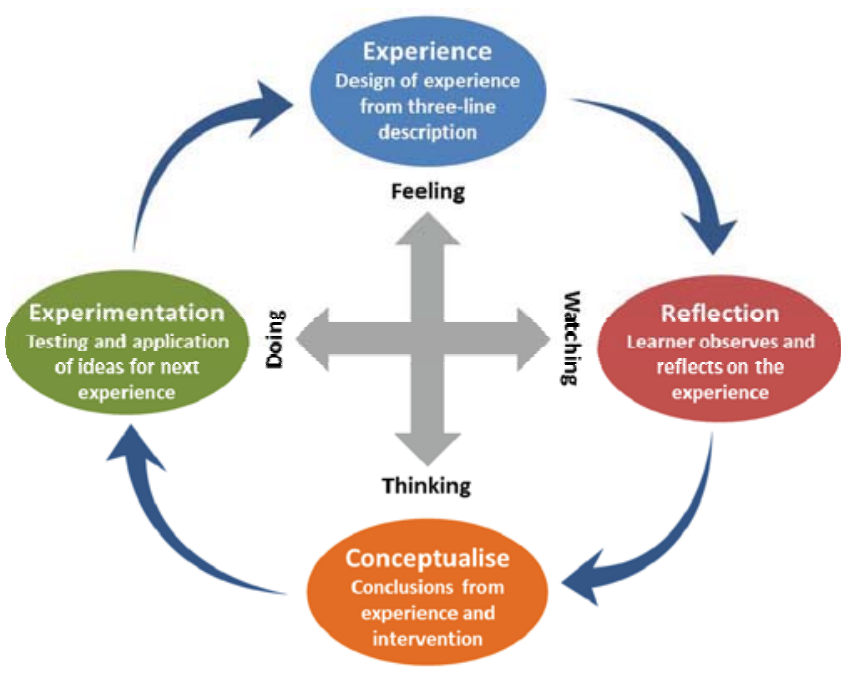

Fig. 1. Four stages of Kolb's experiential learning cycle.

\section{Examples of student work}

To evaluate the effectiveness and impact of the experiential-based and hands-on activities, three assignments were selected as examples of student work. The selection was based on the effective experimental design and measurement techniques, optimum use of resources, impact and successful completion.

\section{- Case 1: X-Band properties of concrete}

In this project, the student investigated the electromagnetic properties of concrete at X-band as a key step towards improving communication systems in urban areas. The properties of a strong concrete mix were analyzed.

A concrete block of size $10 \times 10 \times 35 \mathrm{~cm}$ was used for the experiment. One corner of the block had a copper rod set into the concrete along one of the short axes. A pair of horn antennas was placed on either side in contact with the concrete (Fig. 2). One of the horn antennas was connected to a radiofrequency (RF) signal generator and was used as the transmitter. The other horn (receiver), was connected to a logarithmic detector.

The experiment was conducted by manually sweeping the generator from $6 \mathrm{GHz}$ to $12 \mathrm{GHz}$ in steps of $100 \mathrm{MHz}$. This procedure was performed for three different lateral positions of the pair of horn antennas, one at each end of the concrete block ( $2.5 \mathrm{~cm}$ from the edge), and another was positioned in the centre of the block.

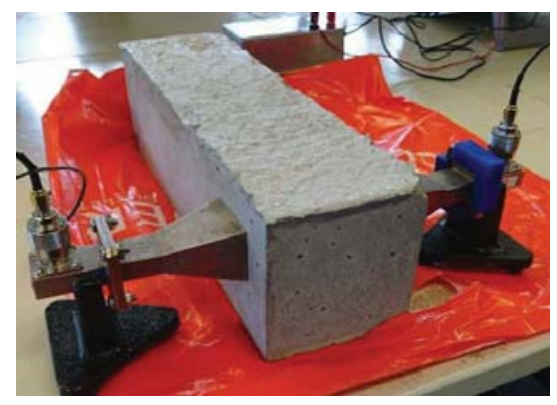

Fig. 2. Isometric view of the apparatus used in the experiment.

Figure 3 shows the received voltage from the logarithmic detector at each measured frequency. The student used the frequency response to calculate the relative permittivity and conductivity of the concrete.

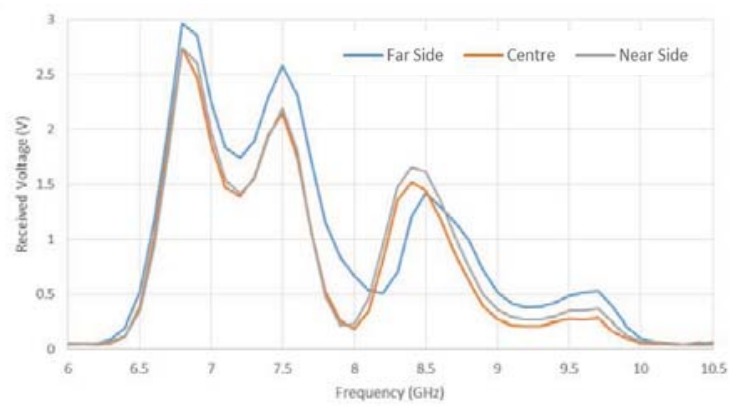

Fig. 3. Frequency response measurements for each of the three sets of measurements. The resonance peaks were used to calculate the electromagnetic properties of the concrete.

The student concluded that the concrete material is a lowloss dielectric in the frequency band $6-10 \mathrm{GHz}$. The relative permittivity and intrinsic impedance of the concrete were calculated to be 3.69 and $196 \Omega$ respectively. This showed good agreement with previous work on various concrete mixes.

- Case 2: Effects of a C-Slot on microstrip patch antenna bandwidth

In this project, the student investigated the effects of the incorporation of a C-slot on the bandwidth of a rectangular microstrip patch antenna. The experimental patch antenna, Fig. 4a, and the C-slot patch antenna, Fig. 4b, were designed to operate at $3.9 \mathrm{GHz}$. The PCB was designed and fabricated 
using simple photolithographic techniques to create conducting layers on the dielectric substrate. The height of the FR4 was $1.6 \mathrm{~mm}$ with a relative permittivity of 4.6.

The bandwidth and central frequency were found via measuring the scattering parameters. The $\mathrm{S}_{11}$ return loss measurements of both antennas (Fig. 5) were determined. The student concluded that the inclusion of a C-slot resonance was reduced from $3.87 \mathrm{GHz}$ to $3.53 \mathrm{GHz}$.

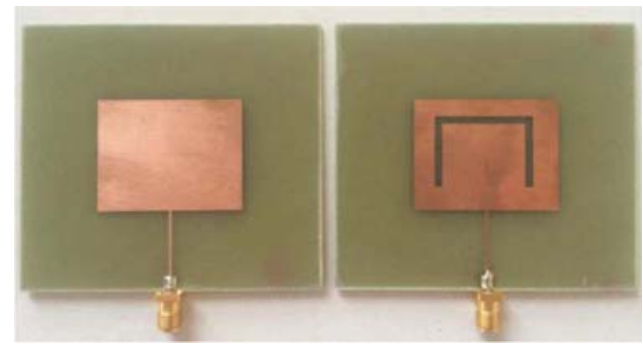

(a)

(b)

Fig. 4. Proposed antennas with quarter wave transformers and SMA connectors: a) Patch antenna and b) c-slotted patch antenna.

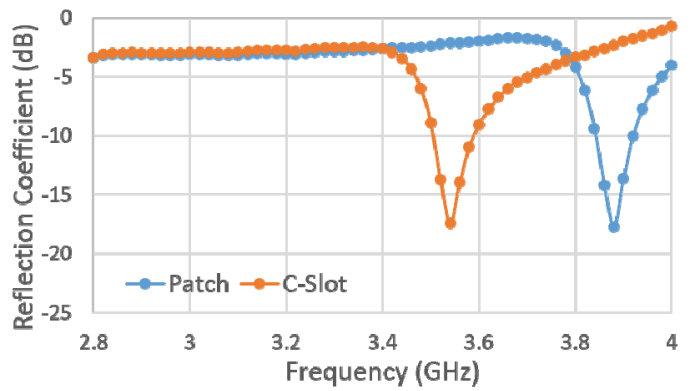

Fig. 5. Return loss of the proposed patch antennas. A frequency shift is evident in both nulls, as well as nulls at higher frequencies.

\section{- Case 3: Cityscape scattering at X-band using a simple collinear monopole antenna}

In this project, the student investigated the effect of reflective surfaces that scatter, absorb and reflect radio waves, and its impact on radio communication systems in urban environments.

A simple collinear, half wave monopole antenna was constructed with a piece of semi-rigid coaxial cable with an unshielded quarter wave extension and tuned using a ferrite bead on the outer conductor. A model city was constructed at a scale of approximately 1:2500. Black cardstock of $200 \mathrm{gsm}$ was used to create structures, and aluminium foil was used to provide RF reflectance. A number of different sized boxes were constructed and lined with the foil to represent the buildings (Fig. 6). Holes were drilled through the ground surface in an approximate grid. The model city (an approximate representation of several actual city blocks in Brisbane, Australia) was set up such that a Gunn Oscillator at $10.5 \mathrm{GHz}$ with a horn waveguide transmitted with the beam directed along the length of the simulated streets (scaled from $4 \mathrm{MHz}$ in the true situation).
The model was placed $15 \mathrm{~cm}$ away from the transmitter to ensure operation in the far-field. Measurements were initially taken at each point of the grid without the buildings, by inserting the antenna (connected to a detector and DC voltmeter) vertically through each hole. After the buildings were placed, the difference in field strength was determined at each point on the grid. A number of blackspots and whitespots were determined. The resulting intensity heatmap is shown in Fig. 7.
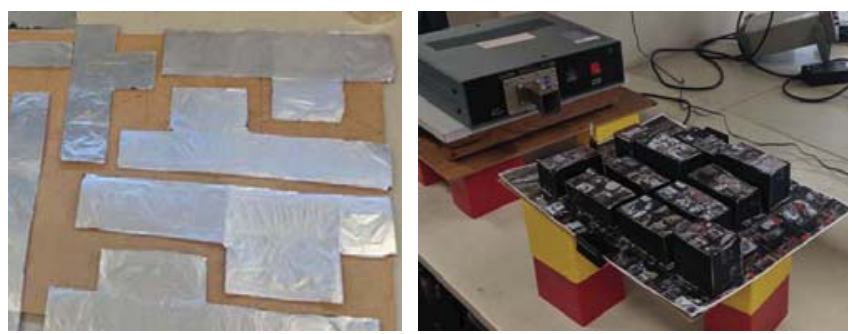

Fig. 6. Set up including Gunn oscillator, model city, antenna, detector (not visible) and voltmeter (not visible).

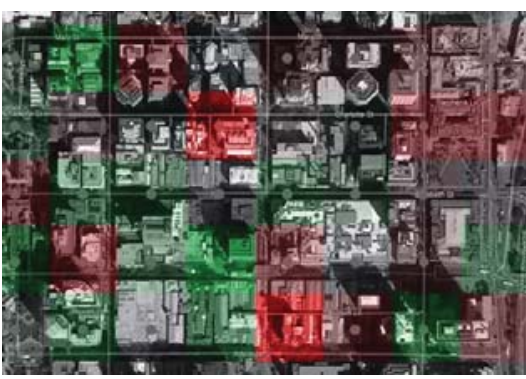

Fig. 7. Attenuation heatmap overlayed on cityscape. The source was located on the centre left of the image. Red signifies an area of low signal strength and green signifies an area of stronger signal srength.

This is in line with the Rayleigh and Rician fading characteristics and multipath ray tracing. The major blackspot had an attenuation loss of $-18.2 \mathrm{~dB}$ compared to the open plane measurements.

The strongest whitespot had an increased field intensity value of $5.8 \mathrm{~dB}$. Given the number of different reflective surfaces, this level of constructive and destructive interference was expected.

\section{E. Student reflections and feedback}

To assess the effectiveness of the experiential learning approach, anonymous student feedback was collected through a general qualitative and quantitative survey containing the following questions:

Q1. This course was well-organized.

Q2. The assessment was clear and fair.

Q3. I received helpful feedback on my assessment work.

Q4. The course engaged me in learning.

Q5. The teaching team was effective in helping me to learn.

The questions were scored using the 5 point likert system, with 5 (strongly agree) to 1 (strongly disagree). With 
a $65 \%$ response rate, undergraduate and postgraduate students completed the survey. Figure 8 summarizes their responses. The 5-point scale was converted to a total score out of 100 .

According to the feedback, students found the course engaging (average score of 92/100), highlighting the support and intervention from the teaching team during the projects.

The students found the experiential learning approach a good way to be exposed to practical applications of communications engineering, they thought the theory complements the practice very well, and although they found the three-line project description very challenging, they felt more rewarded and satisfied at the end of the assessment, than with step-by-step guided laboratory experiences.

Students performed overall much higher in the second assignment, with an average of $65 / 100$ for the first project and $87 / 100$ for the second project. This supports the efficacy of the fourth stage of the learning cycle as students have tested their research hypothesis, building into the creation of new and improved strategies for the following experience.

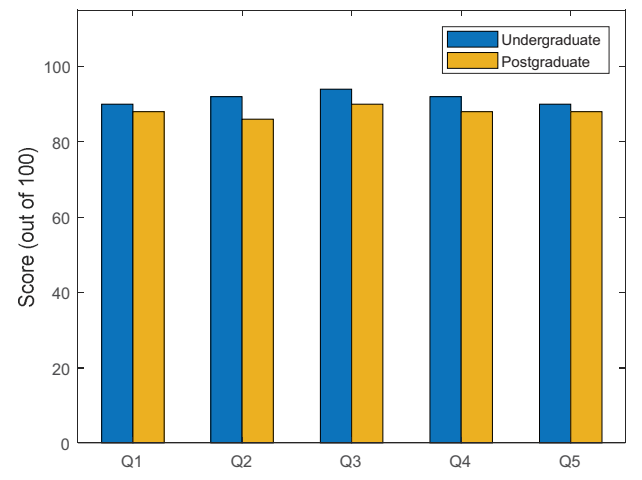

Fig. 8. Anonymous survey response from undergraduate, postgraduate and on-line students. Questions 1 to 5 scored out of 100 .

\section{CONCLUSIONS}

Student engagement is a well-known challenge in student learning. Equipped with a three-line description of a project, students engaged in a learning journey using a self-didactic and creative approach, combined with resources and fundamental theory provided in class. The practical hands-on activities based on Kolb's learning cycle encouraged students to gain a better understanding of wireless communication systems and helped them to project their learning into applications outside the teaching laboratory. The study confirmed an increase in the student-to-student and student-to-instructor interaction, proving that collaborative learning promotes reflection, conceptualization and experimentation in engineering courses.

The qualitative and quantitative feedback from students provided statistical evidence that experiential learning-based courses increase their engagement, enhance their technical knowledge and skills, but also have an impact on their perception towards real-life applications and prospective lines of future employment.

\section{REFERENCES}

[1] $\mathrm{K}$. Wu, "Challenges and opportunities for education in RF/microwaves", IEEE Microwave Magazine, vol. 17, no. 7, pp 1012, July 2016.

[2] B. M. Notaros, "Electromagnetics education and its future and challenges," EuCAP 2019, 13th European Conf. Ant. and Prop., Krakov, Poland, June 2019.

[3] A. Sihvola, "Challenges for electromagnetics teaching and education," FERMAT, Forum for Electromagnetic Research Methods and Application Technologies, Guangzhou, August 2014.

[4] N. Anderson and M. Mina, "A new approach in teaching electromagnetism: How to teach EM to all levels from freshman to graduate and advanced-level students," Proc. American Society for Engineering Education, pp. 1-17, 2003.

[5] P. Crilly, "An innovative approach to teaching an undergraduate electromagnetics, antennas and propagation course," Proc. of the 2014 Zone 1 Conference of the American Society for Engineering Education, IEEE, 2014.

[6] A. Nieves, J. Urbina, T. Kane, S. Huang and D. Penaloza, "Work in progress for developing project-based experiential learning of engineering electromagnetics," ASEE Annual Conference \& Exposition, 2019.

[7] C. Mias, "Electronic problem based learning of electromagnetics through software development," Computer Applications in Engineering Education, vol. 16, no. 1, pp. 12-20, 2008.

[8] M. B. Cohen and A. Zajic, "Revitalizing electromagnetics education with the flipped classroom," USNC-URSI Radio Science Meeting, IEEE, Vancouver, BC, Canada, July 2015.

[9] M. J. Schroeder, A. Kottsick, J. Lee, M. Newell, J. Purcell and R. M. Nelson, "Experiential learning of electromagnetic concepts through designing, building and calibrating a broad-spectrum suite of sensors in a capstone course," Int. Journal of Electrical Engineering Education, vol. 46, no. 2, pp. 198-210, 2009.

[10] J. Leppavirta, H. Kettunen and A. Sihvola, "Complex problem exercises in developing engineering students' conceptual and procedural knowledge of electromagnetics," IEEE Transactions on Education, vol. 54, no. 1, pp. 63-66, 2010.

[11] B. M. Notaros, R. McCullough, S. B. Manic and A. Maciejewski, "Computer assisted learning of electromagnetics through MATLAB programming of electromagnetic fields in the creativity thread of an integrated approach to electrical engineering education," Computer App. in Eng. Education, vol. 27, no. 2, pp. 271-287, 2019.

[12] L. C. Trintinalia, "Simulation tool for the visualization of EM wave reflection and refraction," IEEE Antennas and Propagation Magazine, vol. 55, no. 1, pp. 203-211, 2013.

[13] H. G. Espinosa and D. V. Thiel, "MATLAB-Based interactive tool for teaching electromagnetics," IEEE Antennas and Propagation Magazine, vol. 59, no. 5, pp. 140-146, 2017.

[14] L. Sevgi, "From Engineering Electromagnetics to Electromagnetic Engineering: Teaching/Training Next Generations," EuCAP 2019, 13th European Conf. Ant. and Prop., Krakov, Poland, June 2019.

[15] A. Polo, M. Salucci, A. Gelmini, G. Gottardi, G. Oliversi, P. Rossa and A. Massa, "Advanced teaching in EM - Towards the integration of theoretical skills and applicative/industrial skills", EuCAP 2019, 13th European Conf. Ant. and Prop., Krakov, Poland, June 2019.

[16] D. A. Kolb, "Experimental learning: Experience as the source of learning and development," Enlewood Cliffs, NJ: Prentice Hall, 1984.

[17] J. Ernst, "Impact of Experiential Learning on Cognitive Outcome in Technology and Engineering Teacher Preparation," Journal of Technology Education, vol. 24, no. 2, pp. 31-40, 2013.

[18] C. Manolis, D. J. Burns, R. Assudani and R. Chinta, "Assessing experiential learning styles: A methodological reconstruction and validation of the Kolb Learning Style Inventory," Learning and Individual Differences, vol. 23, pp. 44-52, 2013.

[19] A. Konak, T. K. Clark and M. Nasereddin, "Using Kolb's Experiential Learning Cycle to improve student learning in virtual computer laboratories," Computers \& Education, vol. 72, pp. 11-22, 2014. 